\title{
Model Study of Fluid Flow Phenomena in a Bottom Blown Bath in the Presence of Reverse Emulsification
}

\author{
Manabu IGUCHI, Koya TAKAHASHI, ${ }^{1)}$ Hirotoshi KAWABATA, ${ }^{2)}$ Kiyoto SASAKI," Shin-ichiro \\ YOKOYA ${ }^{3)}$ and Hiromichi KIUCHI
}

Division of Materials Science and Engineering, Graduate School of Engineering, Hokkaido University, North 13, West 8, Kita-ku, Sapporo, Hokkaido, 060-8628 Japan. 1) Graduate Student, Graduate School of Engineering, Hokkaido University, North 13, West 8, Kita-ku, Sapporo, Hokkaido, 060-8628 Japan. $\quad 2$ 2) Graduate School of Engineering, Osaka University, Yamadaoka, Suita, Osaka-fu, 565-0871 Japan. $\quad 3$ ) Department of Mechanical Engineering, Nippon Institute of Technology, Miyashiro, Minami-Saitama, Saitama-ken, 345-8501 Japan.

(Received on July 31, 1997; accepted in final form on June 4, 1998)

\begin{abstract}
Model experiments were carried out to elucidate the behavior of rising bubbles and resultant liquid flow motion in a cylindrical bath agitated by central bottom gas injection. Emphasis was placed on the bubble and liquid flow characteristics in the presence of reverse emulsification, i.e., the slag droplet formation in the lower metal layer. Silicone oil and n-pentane were used as models for top slag and water was used as a model for molten metal. A thin top oily liquid layer was placed on a pool of water. Air was injected through a central single-hole bottom nozzle. The bubble and liquid flow characteristics for the top silicone oil layer were modulated significantly from their respective characteristics in a water bath without a top oil layer. On the other hand, these two characteristics for the $n$-pentane layer were not influenced by the top oil layer at all inspite of the occurrence of the reverse emulsification. The difference of the bubble and liquid flow characteristics between the silicone oil and $n$-pentane layers can be explained by the fact that the fluid flow resistance at the silicone oil/water interface is much larger than that between the $n$-pentane/water interface.
\end{abstract}

KEY WORDS: steelmaking; injection; top slag; reverse emulsification; LDV; electroresistivity probe.

\section{Introduction}

Recently, it has been shown from cold model experiments that the liquid flow characteristics in the recirculation region of a cylindrical bottom blown bath are modulated significantly by the presence of a thin top oil layer regardless of the occurrence of the reverse emulsification of the top oily liquid, i.e., oil droplet formation in the lower layer. ${ }^{1-5)}$ The reason can be explained subsequently. Silicone oils with high viscosity are commonly used to simulate actual top slags. The density of the silicone oils is slightly lower than the density of water, and hence, the reverse emulsification is likely to occur. ${ }^{6-9)}$ The energy transferred from rising bubbles to water is consumed mainly to drive the viscous top oil as well as to generate oil droplets in the water bath. As a result, the contribution of the energy to causing the liquid flow motion in the recirculation region is highly reduced, and thus the recirculation flow is weakened strongly.

Compared with the liquid flow characteristics in the recirculation region, clear explanation of the modulation of the liquid flow characteristics in the bubbling jet region has not been given in the previous investigations. The reason lies in the lack of bubble characteristic data in a bath covered with a thin top oil layer because the bubble characteristics is closely associated with the liquid flow characteristics in the bubbling jet region.

Considering these circumstances, in a companion article, ${ }^{10)}$ we focused on the effects of the physical properties of top oily liquids on the bubble and liquid flow characteristics in the bubbling jet region and carried out water model experiments in the absence of the reverse emulsification using four kinds of silicone oils and npentane. The viscosity of top oily liquid was found to be the most influential parameter for the modulation of the two characteristics. The critical viscosity of the top oily liquid was approximately $10 \mathrm{mPa} \cdot \mathrm{s}^{10}{ }^{10}$

In this study, we used silicone oil and n-pentane as the models for top slag and measured the bubble and liquid flow characteristics using a two-needle electroresistivity probe and a two-channel laser Doppler velocimeter in order to elucidate the role of reverse emulsification on the modulation of the two characteristics.

\section{Experimental Apparatus and Procedure}

A schematic of the experimental apparatus was shown in Fig. 1. The test vessel made of transparent acrylic resin had an inner diameter $D$ of $20.0 \mathrm{~cm}$ and a height $H$ of $39.0 \mathrm{~cm}$. The water bath depth $H_{\mathrm{L}}$ was $30.0 \mathrm{~cm}$, just as in the case of preceding experiments. ${ }^{3-5,10}$ ) Air was 


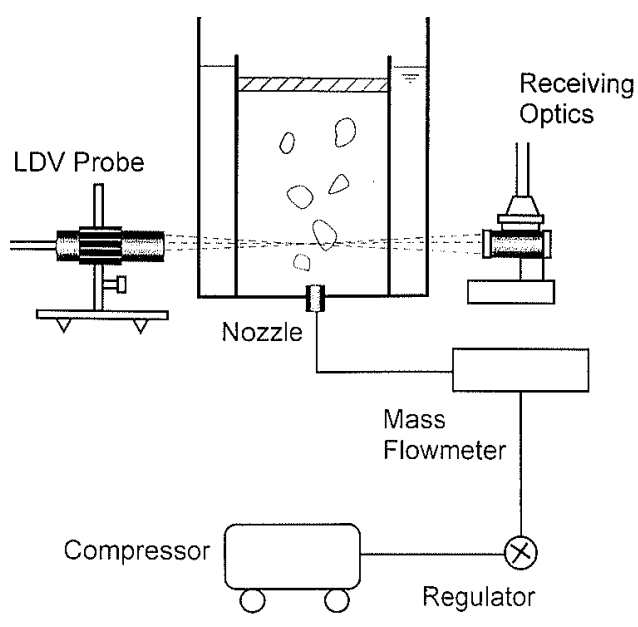

Fig. 1. Experimental apparatus.

Table 1. Physical properties of liquid at $298 \mathrm{~K}$.

\begin{tabular}{llccc}
\hline Liquid & $\begin{array}{c}\text { Density } \\
\left(\mathrm{g} / \mathrm{cm}^{3}\right)\end{array}$ & $\begin{array}{c}\text { Kinematic } \\
\text { viscosity } \\
(\mathrm{cSt})\end{array}$ & $\begin{array}{c}\text { Viscosity } \\
(\mathrm{mPa} \cdot \mathrm{s})\end{array}$ & $\begin{array}{c}\text { Interfacial } \\
\text { tension } \\
(\mathrm{mN} / \mathrm{m})\end{array}$ \\
\hline $\begin{array}{l}\text { Silicone oil } \\
\text { n-Pentane }\end{array}$ & 0.968 & 100 & 97 & 53.0 \\
Water & 0.62 & 0.37 & 0.23 & 57.8 \\
\hline
\end{tabular}

injected through a single-hole bottom nozzle of $0.20 \mathrm{~cm}$ in inner diameter. The origin of the cylindrical coordinate system, $(r, \theta, z)$, was placed at the center of the nozzle exit. The air flow rate $Q_{\mathrm{g}}$ was adjusted by means of a mass flow controller. The thickness of the top oil layer was $2.0 \mathrm{~cm}$. The physical properties of top oily liquids were listed in Table 1.

Two gas flow rates, $Q_{\mathrm{g}}=10$ and $40 \mathrm{~cm}^{3} / \mathrm{s}$, were chosen to generate two different flow patterns in the bath. The reverse emulsification did not take place for $Q_{\mathrm{g}}=10$ $\mathrm{cm}^{3} / \mathrm{s}$, whereas intense reverse emulsification was observed for $Q_{\mathrm{g}}=40 \mathrm{~cm}^{3} / \mathrm{s}$. Oil droplets reached as far as $z \fallingdotseq 20 \mathrm{~cm}$ (approximately $10 \mathrm{~cm}$ beneath the bath surface) for the silicone oil layer, while $z \fallingdotseq 25 \mathrm{~cm}$ (approximately $5 \mathrm{~cm}$ beneath the bath surface) for the npentane layer. The diameter of top oily liquid droplets ranged from less than $1 \mathrm{~mm}$ to approximately $20 \mathrm{~mm}$. The feature of oily liquid droplets in the water bath should be referred to Fig. 2(b) in the previous article. ${ }^{3)}$

An additional water layer of a thickness $2.0 \mathrm{~cm}$ was placed on the original water bath depth of $H_{\mathrm{L}}=30.0 \mathrm{~cm}$. This $2.0 \mathrm{~cm}$ water layer, called the top water layer, was taken up to demonstrate that it does not cause any modulation of the two characteristics.

Bubble characteristics specified by gas holdup $\alpha$, bubble frequency $f_{\mathrm{B}}$, mean bubble rising velocity $\bar{u}_{\mathrm{B}}$, and mean bubble chord legth $\bar{L}_{\mathrm{B}}$ were measured with a two-needle electroresistivity probe. The measurement uncertainty was $\pm 5 \%$ for $\alpha$ and $f_{\mathrm{B}}$ and $\pm 10 \%$ for $\bar{u}_{\mathrm{B}}$ and $\bar{L}_{\mathrm{B}}$. On the other hand, liquid flow characteristics specified by, for example, the axial and radial mean velocities, $\bar{u}$ and $\bar{v}$, were measured using a two-channel laser Doppler velocimeter in the presence of the reverse emulsification. Errors inherent in this method were $\pm 3 \%$.

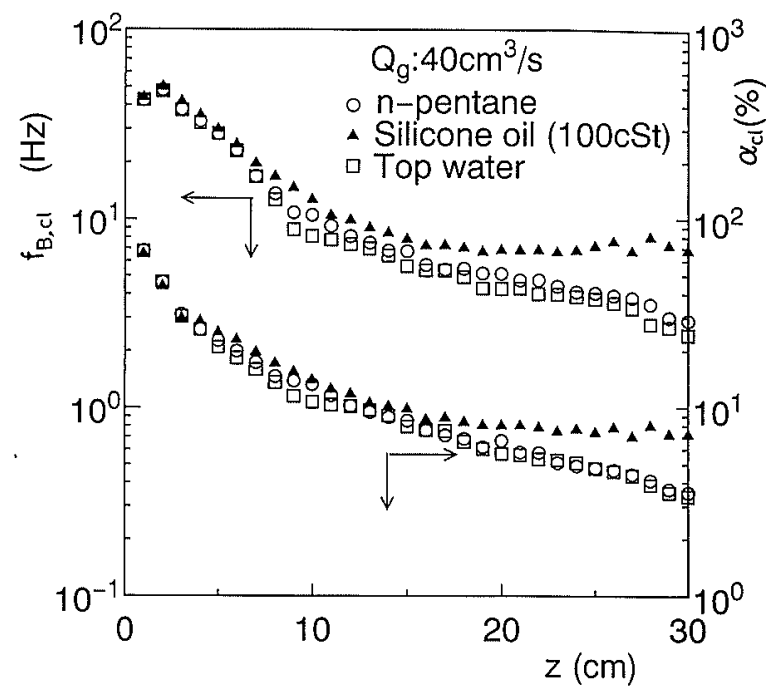

Fig. 2. Centerline values of gas holdup and bubble frequency.

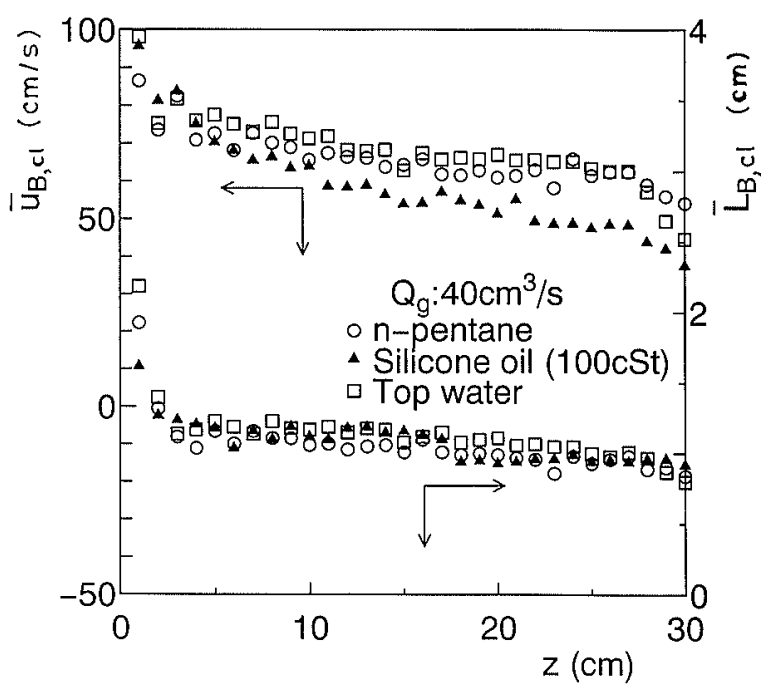

Fig. 3. Centerline values of mean bubble rising velocity and mean bubble chord length.

\section{Experimental Results and Discussion}

\subsection{Bubble Characteristics}

Measured values of gas holdup and bubble frequency on the centerline of the bubbling jet, $\alpha_{\mathrm{cl}}$ and $f_{\mathrm{B}, \mathrm{cl}}$, were shown in Fig. 2, and those of the mean bubble rising velocity and mean bubble chord length, $\bar{u}_{\mathrm{B}, \mathrm{cl}}$ and $\bar{L}_{\mathrm{B}, \mathrm{cl}}$, were plotted in Fig. 3. The $f_{\mathrm{B}, \mathrm{cl}}$ distribution for the silicone oil layer exhibited a minimum value at around $z=18 \mathrm{~cm}$ and a mild peak at around $z=27 \mathrm{~cm}$. The $\alpha_{\mathrm{cl}}$ distribution also exhibits a mild peak around the same axial position as for the $f_{\mathrm{B}, \mathrm{cl}}$ distribution. Such a curious mild peak in the $\alpha_{\mathrm{cl}}$ and $f_{\mathrm{B}, \mathrm{cl}}$ distributions is resulting from the contribution of oil droplets rising in the bubbling jet. The electroresistivity probe cannot distinguish bubbles and oil droplets because the electric conductivity of oil droplets is very low. Consequently, we focused on the centerline values for $z<20 \mathrm{~cm}$ where oil droplets are absent.

In the two figures, the measured values of $\alpha_{\mathrm{cl}}, f_{\mathrm{B}, \mathrm{cl}}$, $\bar{u}_{\mathrm{B}, \mathrm{cl}}$ and $\bar{L}_{\mathrm{B}, \mathrm{cl}}$ for the $\mathrm{n}$-pentane layer agreed with their respective values for the top water layer everywhere on 


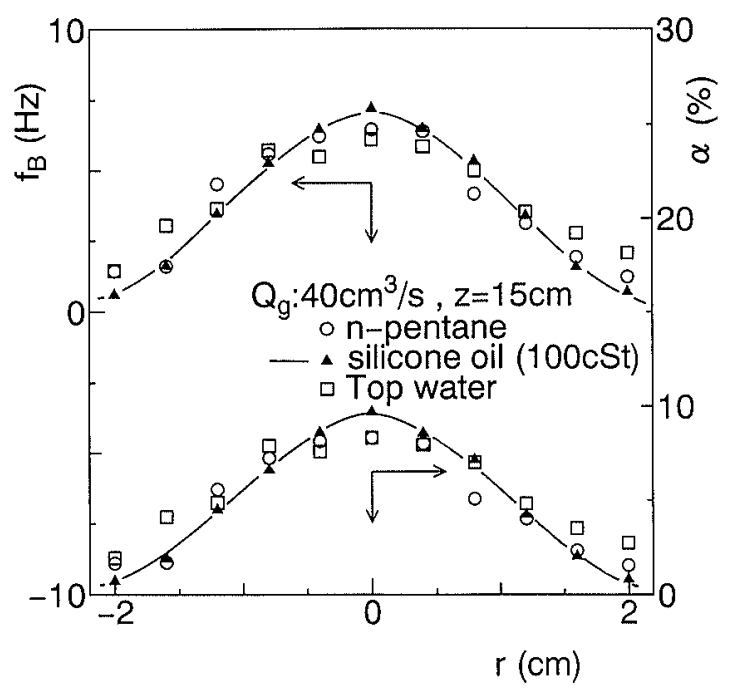

Fig. 4. Radial distributions of gas holdup and bubble frequency.

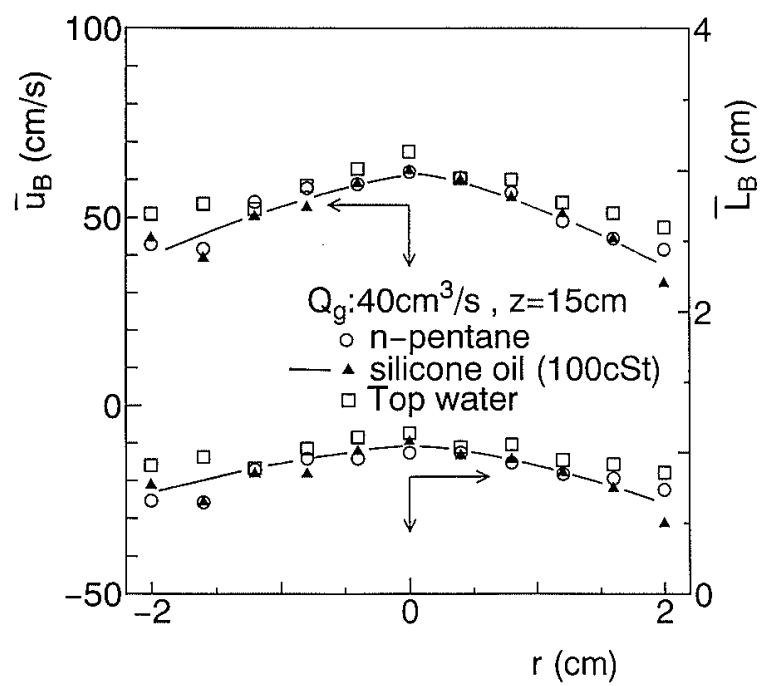

Fig. 5. Radial distributions of mean bubble rising velocity and mean bubble chord length.

the centerline. Accordingly, the top n-pentane layer did not have any influence on the bubble characteristics. On the other hand, the measured values of $\alpha_{\mathrm{cl}}$ and $f_{\mathrm{B}, \mathrm{cl}}$ for the silicone oil layer were slightly larger than for the top water layer. The measured $\bar{u}_{\mathrm{B}, \mathrm{cl}}$ value became slightly lower than for the top water layer in the bath except near the nozzle exit, but the measured $\bar{L}_{\mathrm{B}, \mathrm{cl}}$ value was approximately the same as that for the top water layer, just as in the case of $Q_{\mathrm{g}}=10 \mathrm{~cm}^{3} / \mathrm{s}$ shown in the companion article. ${ }^{10)}$

The radial distributions of $\alpha, f_{\mathrm{B}}, \bar{u}_{\mathrm{B}}$ and $\bar{L}_{\mathrm{B}}$ for $z=15 \mathrm{~cm}$ were shown in Figs. 4 and 5. The measured $\alpha$ and $f_{\mathrm{B}}$ values for silicone oil decreased rapidly in the radial direction unlike the results for the $\mathrm{n}$-pentane and top water layers. All the measured $\bar{u}_{\mathrm{B}}$ values remained almost unchanged in the radial direction. The measured $\bar{u}_{\mathrm{B}}$ values for the silicone oil layer were slightly smaller than those for the remaining two cases.

These data mean that bubbles are likely to flock together around the centerline of the bubbling jet but the rising bubble motion is slightly suppressed due to

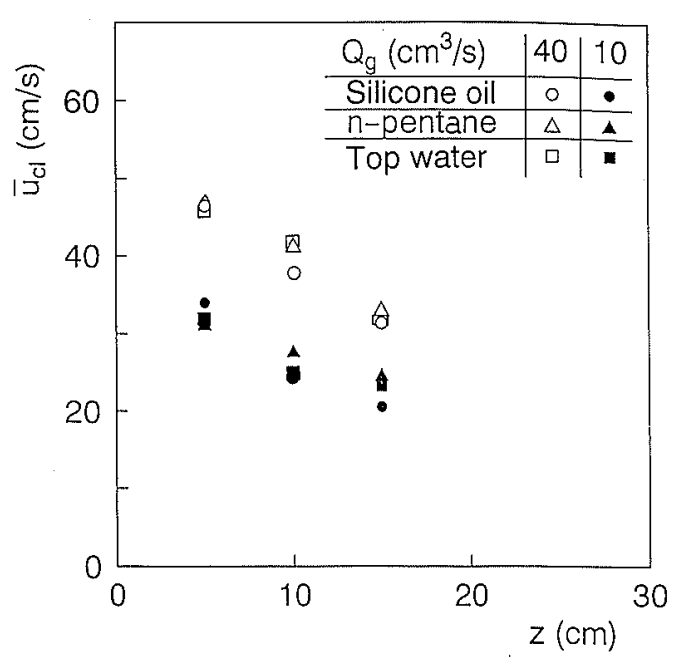

Fig. 6. Centerline values of the axial mean velocity.

interaction between the wakes behind bubbles. The localization of bubbles near the centerline of the bubbling jet was caused by weakened turbulent interaction between the bubbling jet and its surroundings due to the suppression of recirculation motion. ${ }^{10)}$

\subsection{Liquid Flow Characteristics}

\subsubsection{Axial Distributions}

Figure 6 shows measured values of the axial mean velocity on the centerline of the bubbling jet for $Q_{\mathrm{g}}=$ $40 \mathrm{~cm}^{3} / \mathrm{s}$ together with those for $Q_{\mathrm{g}}=10 \mathrm{~cm}^{3} / \mathrm{s}$. As mentioned in the preceding section, the reverse emulsification took place for $Q_{\mathrm{g}}=40 \mathrm{~cm}^{3} / \mathrm{s}$ but did not for $Q_{\mathrm{g}}=10 \mathrm{~cm}^{3} / \mathrm{s}$. The measured $\bar{u}_{\mathrm{cl}}$ values were hardly influenced by the physical properties of the top layer as well as the occurrence of the reverse emulsification.

The root-mean-square (rms) values of the axial and radial turbulence components, $u_{\mathrm{rms}, \mathrm{cl}}^{\prime}$ and $v_{\mathrm{rms}, \mathrm{cl}}^{\prime}$, were shown in Figs. 7 and 8, respectively. The measured $u_{\text {rms,cl }}^{\prime}$ and $v_{\mathrm{rms}, \mathrm{cl}}^{\prime}$ values for $Q_{\mathrm{g}}=10 \mathrm{~cm}^{3} / \mathrm{s}$ were not influenced by the top oil layer, but in the case of the silicone oil layer those for $Q_{\mathrm{g}}=40 \mathrm{~cm}^{3} / \mathrm{s}$ became to increase as $z$ increased. This fact implies that the interaction among the wakes behind bubbles becomes violent because of the localization of bubbles along the centerline of the bubbling jet for the silicone oil layer.

\subsubsection{Radial Distributions}

The radial distributions of the axial mean velocity $\bar{u}$ measured at $z=15 \mathrm{~cm}$ were shown in Fig. 9. Any one of the top layers did not modulate the radial $\bar{u}$ distributions for $Q_{\mathrm{g}}=10 \mathrm{~cm}^{3} / \mathrm{s}$, whereas for $Q_{\mathrm{g}}=40 \mathrm{~cm}^{3} / \mathrm{s}$ only the measured $\bar{u}$ value for the silicone oil layer decreased rapidly in the radial direction. Although the reverse emulsification took place for the n-pentane layer for $Q_{\mathrm{g}}=40 \mathrm{~cm}^{3} / \mathrm{s}$, the radial $\bar{u}$ distribution was not modulated at all.

Figure 10 shows the rms values of the axial turbulence component measured at $z=15 \mathrm{~cm}$. Even in the absence of the reverse emulsification $\left(Q_{\mathrm{g}}=10 \mathrm{~cm}^{3} / \mathrm{s}\right), u_{\mathrm{rms}}^{t}$ for the silicone oil layer decreased rapidly in the radial direction. Accordingly, the axial turbulence component is more sensitive to the existence of the top silicone oil layer than 


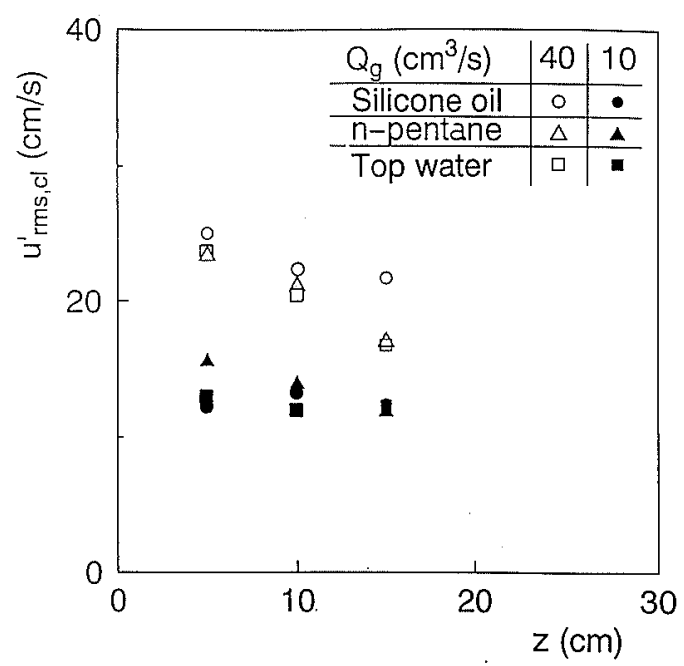

Fig. 7. Centerline values of the root-mean-square values of the axial turbulence component.

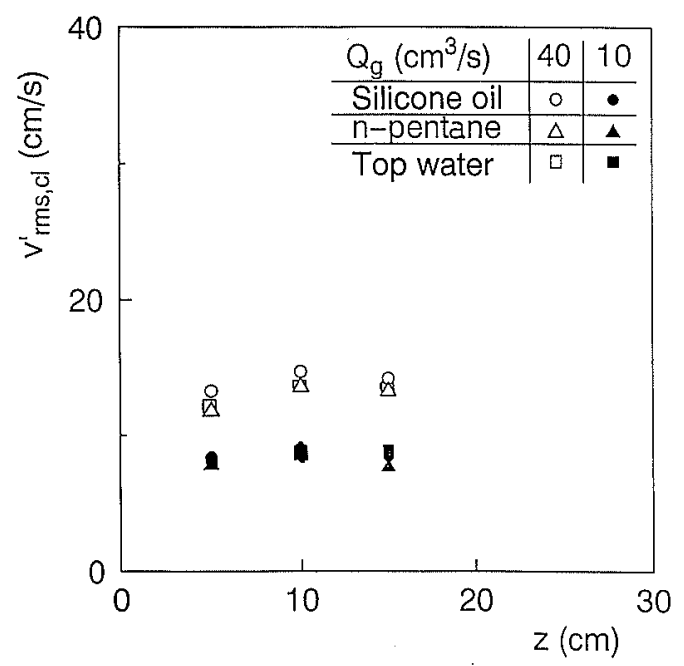

Fig. 8. Centerline values of the root-mean-square values of the radial turbulence component.

the axial mean velocity component $\bar{u}$. On the other hand, in the presence of the reverse emulsification $\left(Q_{\mathrm{g}}=\right.$ $40 \mathrm{~cm}^{3} / \mathrm{s}$ ), the measured $u_{\mathrm{rms}}^{\prime}$ value for the silicone oil layer became larger around the centerline than those for the remaining two cases because of the above-mentioned localization of rising bubbles. Also in this case, the measured $u_{\mathrm{rms}}^{\prime}$ value for the silicone oil layer decreased rapidly in the radial direction, but the $u_{\mathrm{rms}}^{\prime}$ value for the n-pentane layer was not affected by the reverse emulsification.

The same conclusions as for the radial $u_{\mathrm{rms}}^{\prime}$ distribution were obtained for the rms values of the radial turbulence component, $v_{\text {rms }}^{\prime}$, as demonstrated in Fig. 11.

Figure 12 shows that the Reynolds shear stress only for the top silicone oil layer decreased rapidly in the radial direction.

The magnitudes of the three turbulence components of flow in a bottom blown bath are usually comparable to the mean velocity component in the main stream direction or higher than it. In order to describe the characteristics of the turbulence components in detail, it is desirable to discuss about higher correlations such as the skewness and flatness factors.

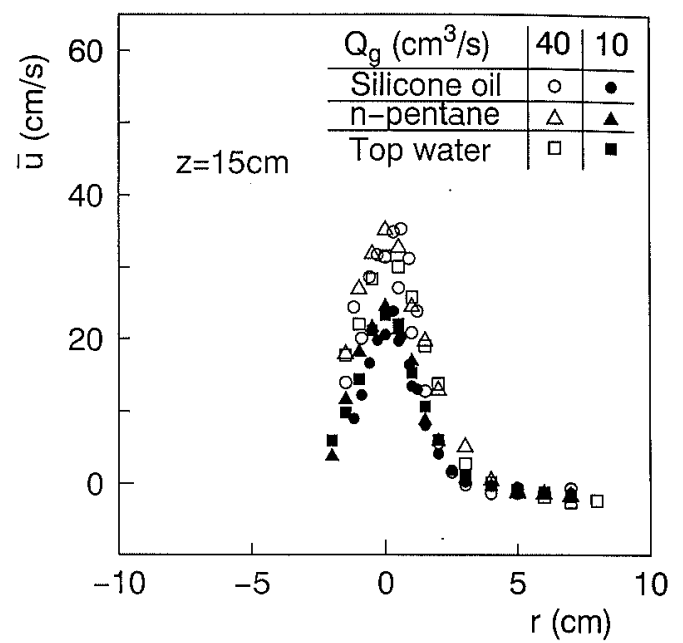

Fig. 9. Radial distributions of the axial mean velocity.

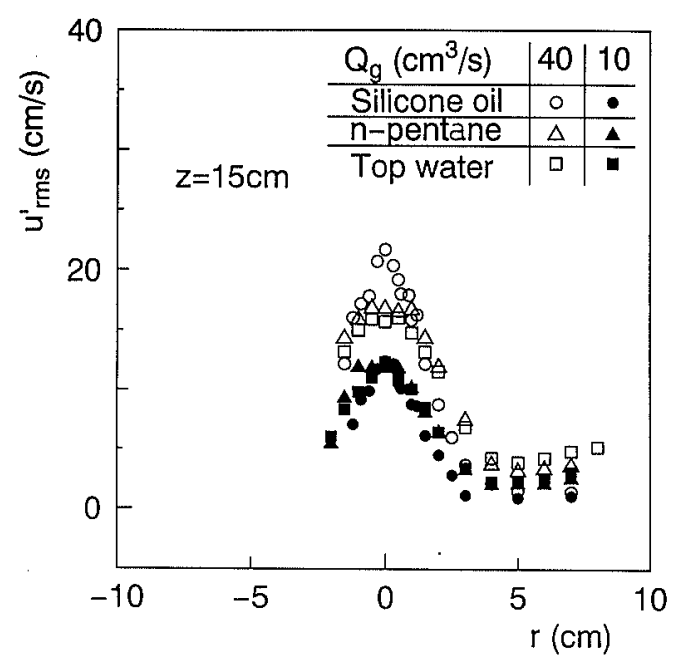

Fig. 10. Radial distributions of the root-mean-square value of the axial turbulence component.

Figures 13 and 14 show the skewness factors for the axial and radial turbulence components, $S_{\mathrm{u}}$ and $S_{\mathrm{v}}$. The skewness factor is one of measures for characterizing the probability distribution function of turbulence components. Details of this factor should be referred to the previous article. ${ }^{4)}$ The broken line in each figure designates the measured value for a single-phase free jet measured by Wygnanski and Fiedler (abbreviated as W-F).

It should be noted that the broken line was drawn for $r / b_{u}<2.5$. The main reason is that the axial and radial velocity components become very small for $r / b_{\mathrm{u}}>2.5$ and accordingly reliable data on the skewness and flatness factors cannot be obtained.

The dependence of the presently measured values of $S_{\mathrm{u}}$ and $S_{\mathrm{v}}$ on the radial coordinate $r$ changed drastically at $r / b_{\mathrm{u}} \fallingdotseq 2$. This is because the boundary between the bubbling jet region and the recirculation region is located at $r / b_{\mathrm{u}} \fallingdotseq 2$. As the fluid flow in the recirculation region is affected by the side and bottom walls, the turbulence structure in this region is different from that in the bubbling jet region. In addition, the number of data on the skewness and flatness factors in the recirculation 


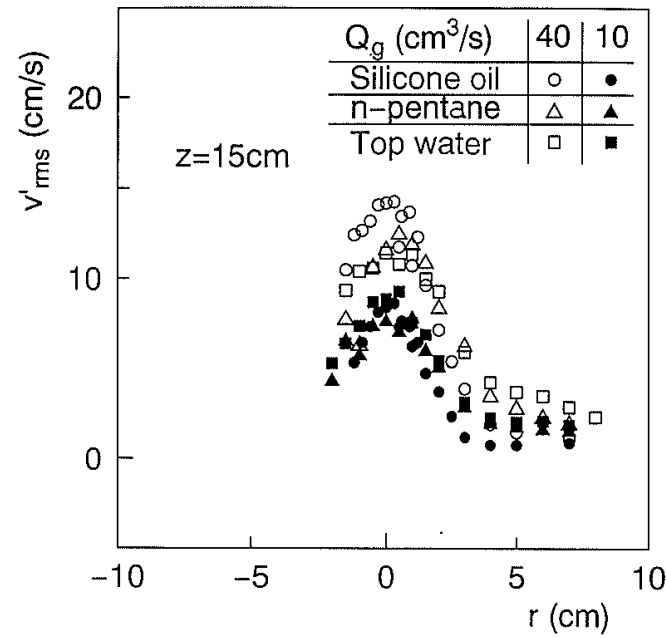

Fig. 11. Radial distributions of the root-mean-square value of the radial turbulence component.

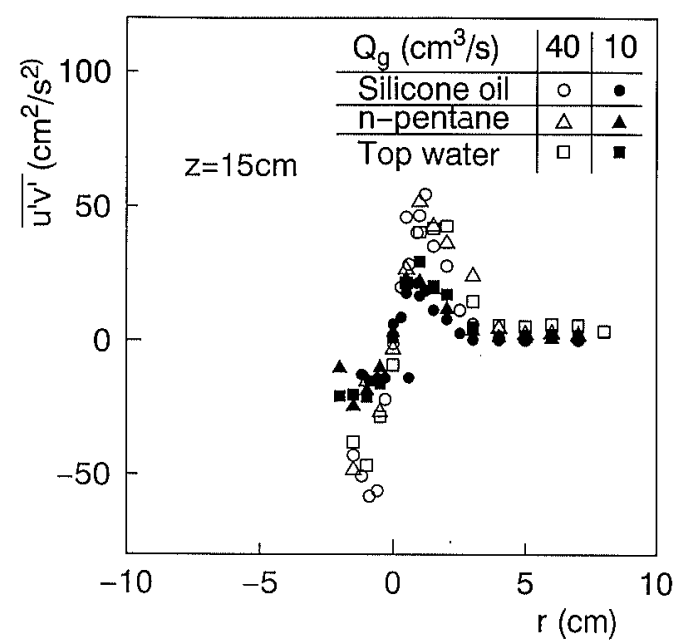

Fig. 12. Radial distributions of the Reynolds shear stress.

region, $r / b_{\mathrm{u}}>2$, is limited. Considering these circumstances, we focus solely on the bubbling jet region.

In the bubbling jet region, $r / b_{\mathrm{u}}<2$, in Fig. 13, the measured $S_{\mathrm{u}}$ values for the n-pentane and top water layers almost agreed with each other. The difference between these two-phase jet data and the broken line for the single-phase free jet is caused by additional turbulence production in the wake of rising bubbles. The measured $S_{\mathrm{u}}$ values for the silicone oil layer approached the broken line for the single-phase jet value. This is probably because the turbulence structure inherent in the wake of bubbles is destroyed by the interaction of the wakes of bubbles. This fact, however, does not directly mean that the turbulence structure approaches the structure of a single-phase free jet because the mechanism of turbulence production is different between the two types of jets.

In Fig. 14, all the measured $S_{\mathrm{v}}$ values for the radial turbulence component agreed with one another and yet agreed with the broken line in the bubbling jet region. Consequently, the radial turbulence component in the bubbling jet region is less influenced by the top oil layer than the axial turbulence component.

Figures 15 and 16 show the flatness factors for the ax-

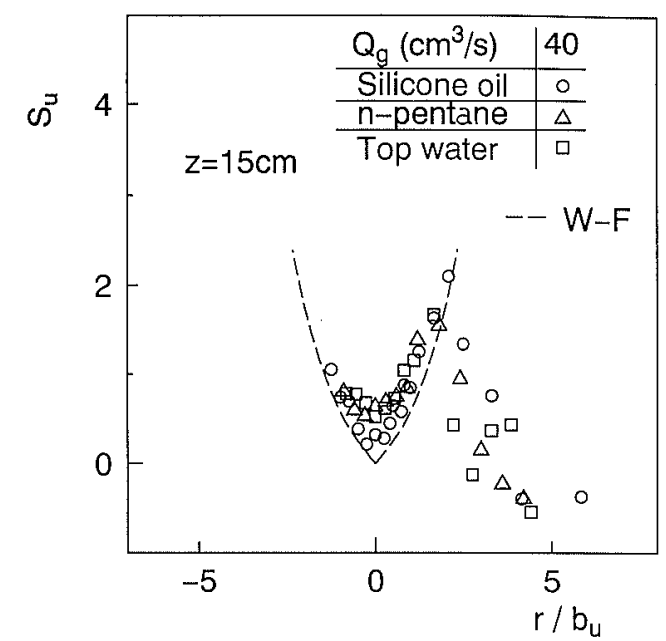

Fig. 13. Radial distributions of the skewness factor for the axial turbulence component.

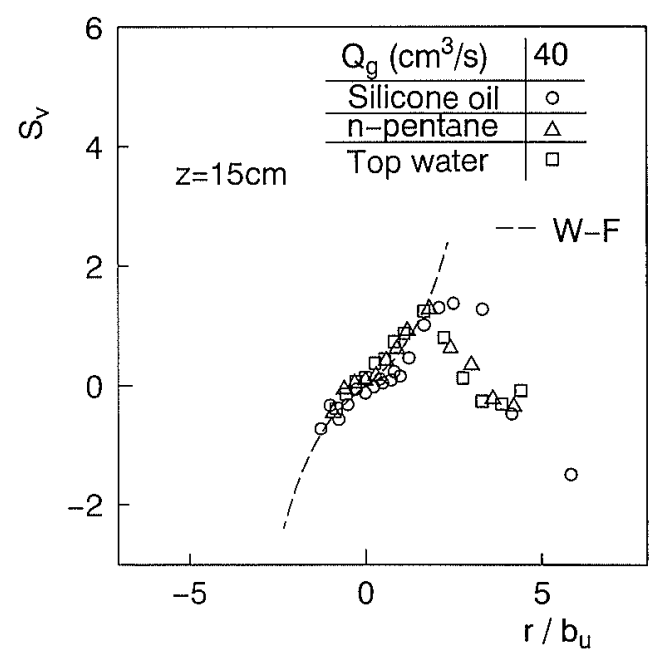

Fig. 14. Radial distributions of the skewness factor for the radial turbulence component.

ial and radial turbulence components, $F_{\mathrm{u}}$ and $F_{\mathrm{v}}$. In the bubbling jet region, only the $F_{\mathrm{u}}$ values for the silicone oil layer were influenced by the top layer in the same manner as mentioned about the skewness factors. The data on $F_{v}$ for the silicone oil are much different from those for the n-pentane and top water. Such a difference may be caused by many silicone oil droplets existing above this axial measurement position. A definite explanation should be discussed after accumulating more data.

\section{Concluding Remarks}

(1) A top n-pentane layer did not modulate the bubble and liquid flow characteristics at all regardless of the presence of the reverse emulsification. This is because the viscosity of $n$-pentane is approximately one fourth of the water value, and hence, the energy transferred from rising bubbles to water in the bath is hardly consumed to drive the top n-pentane even if oil droplets are generated and trapped in the bath. That is, most of the energy is consumed to drive water in the recirculation region. This fact implies that the bubble and liquid 


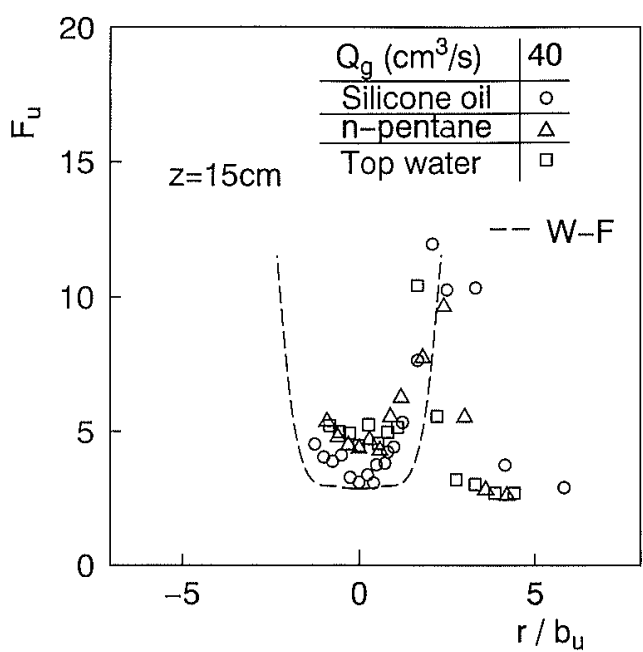

Fig. 15. Radial distributions of the flatness factor for the axial turbulence component.

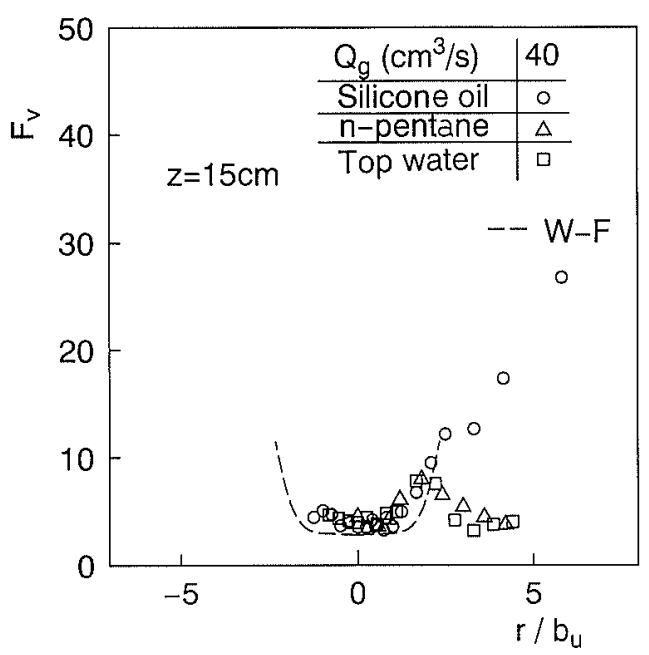

Fig. 16. Radial distributions of the flatness factor for the radial turbulence component.

flow characteristics in actual refining processes are not affected by the top slag layer even if the reverse emulsification takes place as long as the viscosity of the top slag is smaller than that of molten steel.

(2) According to the previous investigations on the effects of the physical properties of top oily liquid on the bubble and liquid flow characteristics, ${ }^{10)}$ the interfacial tension between the oily liquids and water did not have any influence on the two characteristics as far as water model experiments are concerned. The most influential parameter was the viscosity of the top oily liquid. When the viscosity of top oily liquid exceeded approximately $10 \mathrm{mPa} \cdot \mathrm{s}$ and the occurrence of the reverse emulsification of the top oily liquid was absent, the energy supplied by rising bubbles to water was mostly consumed to drive the top oily liquid. The recirculation flow therefore was suppressed to a great extent and turbulent interaction between the bubbling jet and the recirculation flow became weak. As a result, bubbles localized near the centerline of the bubbling jet. This localization of bubbles was the main reason for the modulation of the bubble and liquid flow characteristics in the bubbling jet region. In particular, the axial turbulence component was modulated most significantly. This is closely associated with the interaction of turbulent wakes behind bubbles.

The above-mentioned findings obtained in the previous study ${ }^{10)}$ and the present findings collectively show that the occurrence of the reverse emulsification of top oily liquid with a viscosity higher than approximately $10 \mathrm{mPa} \cdot \mathrm{s}$ promotes the modulation of the bubble and liquid flow characteristics in the bubbling jet region. This can be explained subsequently. When the viscosity of a top oily liquid is greater than approximately $10 \mathrm{mPa} \cdot \mathrm{s}$, most of the energy transferred from rising bubbles to the water near the bubbles is used to drive the top oily liquid and the recirculation flow is highly suppressed even in the absence of the reverse emulsification for $Q_{\mathrm{g}}=10 \mathrm{~cm}^{3} / \mathrm{s}$. When the gas flow rate $Q_{\mathrm{g}}$ is increased to $40 \mathrm{~cm}^{3} / \mathrm{s}$, an additional part of the energy is used to generate top oily liquid droplets, and hence, the energy supplied to drive the water in the recirculation region becomes smaller than that in the absence of the reverse emulsification. Accordingly, the bubble and liquid flow characteristics in the bubbling jet region in the presence of the reverse emulsification are more significantly modulated than those in the absence of the reverse emulsification. However, quantitative evaluation of the contributions of the energy to driving the top oily liquid, generating top oily liquid droplets, and driving the water in the recirculation region cannot be made at present.

(3) The direct application of the present findings to the real processes is not justified because the effects of other parameters such as the density ratio are not clear at present. Qualitative evaluation of the effects of the other parameters should be referred to the previous article. $^{3)}$

\section{REFERENCES}

1) D. Mazumdar, H. Nakajima and R. I. L. Guthrie: Metall. Trans.B, 19B (1988), 507

2) H. Nakajima and R. I. L. Guthrie: Tetsu-to-Hagané, 73 (1987), S 950 .

3) M. Iguchi, O. J. Ilegbusi, H. Ueda, T. Kuranaga and Z. Morita: Metall. Mater. Trans. B, 26B (1996), 37.

4) M. Iguchi, T. Nakatani and H. Ueda: Metall. Mater. Trans. B, 28B (1997), 87.

5) O. J. Ilegbusi, M. Iguchi, K. Nakajima, M. Sano and M. Sakamoto: Metall. Mater. Trans. B, 29B (1998), 211.

6) F. Gerlach and M. G. Frohberg: Steel Res., 64 (1993), 7.

7) M. Iguchi, Y. Sumida, R. Okada and Z. Morita: ISIJ Int., 34 (1994), 164.

8) Z. Lin and R. I. L. Guthrie: Metall. Mater. Trans. B, 25B (1994), 855.

9) P. Draegemeier, M. Neifer and S. Roedl: Steel Res., 66 (1995), 194.

10) M. Iguchi, K. Takahashi, O. J. Ilegbusi, M. Sano and H. Kiuchi: ISIJ Int., 38 (1998), 1032. 